\title{
33
}

\section{Discussion Group 1 - IT in curriculum and courseware development}

\author{
Chair: Peter Bollerslev (Denmark) \\ Rapporteurs: Margaret Niess (USA), Paul Nicholson (Australia), \\ Márta Turcsányi-Szábo (Hungary)
}

Participants: Olayele Adelakan (Finland), Deane Arganbright (Papual New Guinea), Ben Awuah (Botswana), Ann Baillie (Zimbabwe), Rachel Cohen (France), Klaus-D Graf (Germany), Jacqueline Grierson (Zimbabwe), Hildigunnur Halldorsdottir (Iceland),Anne McDougall (Australia), Richard Simango (Zimbabwe), Matti Sinko (Finland), David Squires (UK)

GROUP 1A CURRENT SITUATION

\subsection{International Experiences}

Psychology shows that access to new media at this age is easy. Children do not yet build resistance to new media and are not biased. International research shows that small children can use and love to use computers, and take benefit from this.

Why it is important to start early:

1. Develop literacy;

2. Develop personal skills (thinking process, creativity and communication);

3. Learn to use technology and develop basic skills;

4. Integrate of application software.

Numerous countries have started as early as kindergarten with unexpected and encouraging results.

\section{Literacy}

- Computers facilitate writing, illustrating stories, listening to stories on CDROMs. 
- Specific programs and word processors can be used by young children. Many are available on the market but if no funds are available, experience has proved that standard software that comes with the computer is as good.

\section{Developing personal skills (thinking process, creativity, and communication)}

- $\quad$ Problem solving programs help develop reasoning with computers.

- Children are able to use spreadsheets and databases. Easy ones are available (in Denmark, England, Netherlands and the USA) particularly used in environmental studies, science and mathematics.

- Use Logo environment for visual problem solving.

- Programs such as 'Writer's Helper' assist in the development of creative writing.

- Use standard drawing programs (create pictures, illustrate text).

- Use multimedia for creative purposes (e.g. creating stories, animation, music).

- Use Internet for communication and information retrieval.

- Use application programs in subject areas.

\section{Learn to use technology}

Through literacy programmes and programmes designed to develop personal skills children learn to use technology and these approaches are integrated into everyday life.

\section{Integration of application software}

Application software can play a vital role in the education of young children:

- applications in the different subject areas (such as packages that are created for curriculum use);

- integration of IT across the curriculum;

- multidisciplinary projects carried out using IT, multimedia and Internet.

\section{2 Local conditions}

Each country should analyze (a) the local situation and availability, (b) determine goals, and (c) identify the useful application and priorities, taking into account the traditions, cultures and existing strategies.

(a)The local situation and availability:

- situation of schools: electricity, etc.

- equipment available, hardware and software.

- human resources: support of local administration and principal of school; motivation and willingness of teachers; technicians, involvement of parents. 


\section{Courseware}

In Zimbabwe:

- There is very little courseware development.

- Most (all) books are of UK origin - textbooks related to examination syllabuses.

- Most curriculum materials are locally made.

\section{Software}

In Zimbabwe:

- Older versions of conventional applications software (DOS 5.0 WordPerfect, Lotus, dBase, etc.) are the most common.

- There is little funding for software development.

- There is very little subject-specific software.

\section{Collegiality}

In Zimbabwe:

- User groups and links to computing associations are not well developed.

- Very limited forums for discussion are available.

\section{Hardware}

In Zimbabwe:

- Many schools do not have computers.

- A small number of state and private schools do have computers - this contrasts strongly with developed countries, e.g., European countries typically have pupil/computer ratios of about $7: 1$

\section{PHASE 2 - WHAT CAN CHANGE?}

\section{Curriculum}

The examination system is an inherent part of the education system. Parents and students expect courses to be certificated; in particular, computing courses are expected to be certificated as they provide vocational qualifications. It is very unlikely that this situation can change in the medium-term future and formal examinations in computing will remain an established feature of the curriculum. However, some changes in other subject areas through the use of Information Technology (IT), e.g., data logging in Physics, can result in curriculum changes through the use of IT across the curriculum.

\section{Hardware}

There are three possible ways in which hardware provision may be changed:

1. The price of computers may be reduced. Possible approaches here include increased use of cloned machines and a reduction in duty paid to foreign imports. 
(b) Determine goals.

(c) Identify the useful application and priorities, taking into account the traditions, cultures and existing strategies.

\section{RECOMMENDATIONS}

- Educational policy should define the goals before actions such as choosing hardware and software are taken.

- Introduction of IT into education should start as early as preschool, when available, in order to enhance development of children's potential, prevent illiteracy and school failure, and enhance computer literacy

- In elementary schools no definite curriculum should be designed in IT; IT should be integrated into all subjects.

- The use and enrichment of IT skills should be continued throughout schooling to provide a continuous involvement with technology for everyday life.

- Resources should be converted to standardized equipment to facilitate training and exchange of experiences.

- Special attention should be made in the choice of existing software, taking into account the local conditions and culture as well as the educational potential of software. Creation of software, national and/or regional, and cooperation between nations should be encouraged.

- Computers should not be introduced into schools unless they comes with appropriate teacher education and technical support. In certain countries it has been a fruitful solution to organize mobile computer classes, where computers are installed in busses and move around a region together with an experienced teacher.

- Promising schools should be encouraged and supported to serve as models for other schools. Concentrating supporting in such model schools would become a consulting and resource center for other schools as well.

- Schools should be encouraged to find partners in other countries to exchange ideas, software, literature and experiences.

\section{GROUP 1B}

We shall use the framework presented by Paul Nicholson in his workshop on scenario planning to consider issues under four headings: curriculum, hardware, courseware and collegiality.

\section{Curriculum}

In developed countries (e.g., UK, Denmark and Australia) the prevailing rationale is to integrate IT into the curriculum. In Zimbabwe IT/computing is conceived of as a separate subject: e.g., computer literacy courses and examination courses in computing. 
Teacher educators have to adopt, implement and model the appropriate use of IT (Underwood, 1996). This is critical as research also shows that teachers often 'teach with, and what, they were taught'.

Currently, many teacher educators and university staff see IT as either a tool for learning computer science, or as a support for social and economic progress. Little consideration is given to its value in education. Often the technology leads the learning process (learning about the technology) instead of learning with the technology. A lack of emphasis on software evaluation and associated pedagogy, and access to model classrooms is common.

There are a number of critical factors which can be changed in order to help to develop a suitable environment for the adoption of IT in education:

- Develop organic, flexible, responsive plans that allow for both local concerns and national priorities rather than centrally imposed models.

- Develop regional consortia to plan for curriculum and infrastructure projects as this may result in reduced costs.

- Upgrade the competencies of teacher educators in the use of IT in education.

- Make ongoing teacher education a key focus of the implementation process.

- Change the culture of teachers from being deliverers of imposed curricula to reflective, action-research focused practitioners (Elliot, 1981), who can develop localised, contextually and culturally relevant materials.

\section{HOW COULD CHANGE BE IMPLEMENTED?}

The aim of this plan is to develop an organic, flexible, collaborative and responsive system that allows for both local concerns and national priorities to be addressed by local communities or government as appropriate.

\section{Short term (1-2 years)}

- Identify and clarify relevant national priorities in IT in education.

- Identify prospective funding and development partners, and commence planning.

- Identify and train a core of teachers to design and implement short-term 'cascade model' professional development programmes based on the UNESCO curriculum (Tinsely and van Weert, 1994) guidelines.

- Design and develop the materials for the short-term professional development programs.

- Mandate minimum IT competencies for newly-graduating teachers.

- Invest more heavily in teacher education programmes.

- Plan dissemination processes for sharing ideas, materials and projects on IT e.g., conferences, journals, newsletters, etc. 
2. More money may become available: overseas aid, increased government expenditure, donations. (Note that the donation of old equipment causes severe problems - maintenance is expensive or impossible, configurations are inadequate to support appropriate software and shipping costs are often prohibitive.)

3. Reconsider hardware configurations, e.g., the use of palmtops and the use of lower configuration desktop machines in networked environments.

\section{Courseware}

Locally-produced material offers a chance for producing more courseware, courseware which is directly relevant to local needs. As IT is used in other subject areas, e.g., data logging, the content of published courseware such as textbooks will change. Syllabi will also change to reflect the use of IT.

\section{Collegiality}

This may be increased by the formation of local and national teacher groups and groups sponsored by international organisations such as IFIP. The Internet provides opportunities for virtual peer group interaction and continuing professional development programmes also offer opportunities for collaboration.

\section{GROUP 1C}

\section{$1 \quad$ INTRODUCTION}

Many international research articles show that teacher education plays a critical role in the successful adoption of educational innovations such as the use of IT in education. This has significant implications for planning for IT in education. Planners often think that teacher professional development is not needed because it is assumed that normal classroom pedagogy can be transferred directly to the technological medium. This is incorrect. Teacher change is gradual, and requires a change of knowledge, teaching strategies and beliefs as well as the addition of IT skills (Fullan, 1991).

The Concerns-based Adoption Model (Hall, Loucke and Rutherford, 1977) also shows that teachers will only be effective change agents if the change addresses their immediate concerns. In many developing countries, teachers and schools face significant problems in regard to IT - including little, if any, exposure to or experience with computers. They also face the lack of specialist IT teachers to work with and to learn from, lack of essential infrastructure and little awareness of appropriate models of use.

Planners must accept these findings and include them in their thinking about planning for IT as well as accepting the idea that teachers will be the people who will bring their plans into reality. They will have to start to invest in people as well as hardware and software. 
Medium term (3-5 years)

- Develop localised cross-disciplinary teams to identify local priorities, needs and concerns.

- Develop mentor links with teacher education institutions.

- Develop localised, contextualised materials for teachers and students.

- Identify and develop culturally-relevant models of use.

- Develop localised professional development models and materials - e.g., modify the 'cascade' model materials for local conditions.

- Develop the infrastructure for all schools to be able to incorporate computers into their curriculum.

- Develop the infrastructure for widescale networking.

Long term (ongoing)

Use computer networks to establish widescale professional development programmes and curriculum development projects.

\section{REFERENCES}

Elliot, J. (1981) Action-Research: a framework for self-evaluation in schools. Cambridge University Press, Cambridge.

Fullan, M. (1991) The New Meaning of Educational Change. Teachers College Press, New York.

Hall, G., Loucke, H. and Rutheford, W. (1977) Measuring stages of concern about an innovation. University of Texas Research and Development Center for Teacher Education, Austin, TX.

Tinsley, J.D. and van Weert, T.J. (eds.) (1994) Informatics for secondary education, a curriculum for schools. UNESCO, Paris.

Underwood, J. (1996) Teacher education for primary and secondary schools, in (eds. Samways, B \& van Weert, T.) IFIP: Window to the future. WCCE95. Postconference report. Aston University, Birmingham, UK. 